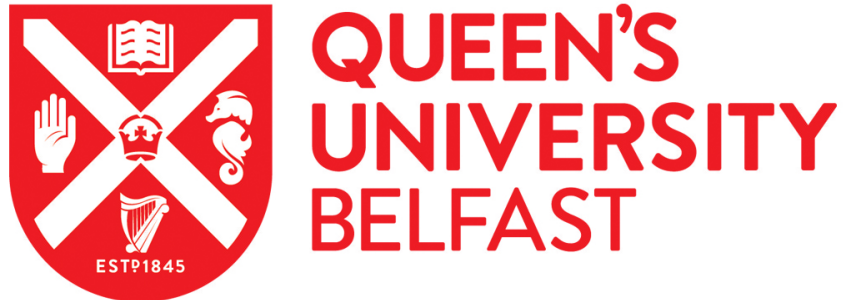

\section{Experimental Investigation of Non-Line-of-Sight Channels in an Intra- Body Network at $2.38 \mathrm{GHz}$}

El-Saboni, Y., Zelenchuk, D., Conway, G., \& Scanlon, W. (2019). Experimental Investigation of Non-Line-ofSight Channels in an Intra-Body Network at $2.38 \mathrm{GHz}$. In 2019 International Workshop on Antenna Technology (iWAT) (pp. 67-69). Institute of Electrical and Electronics Engineers Inc..

https://doi.org/10.1109/IWAT.2019.8730634

Published in:

2019 International Workshop on Antenna Technology (iWAT)

Document Version:

Peer reviewed version

Queen's University Belfast - Research Portal:

Link to publication record in Queen's University Belfast Research Portal

Publisher rights

Copyright 2019 IEEE. This work is made available online in accordance with the publisher's policies. Please refer to any applicable terms of use of the publisher.

\section{General rights}

Copyright for the publications made accessible via the Queen's University Belfast Research Portal is retained by the author(s) and / or other copyright owners and it is a condition of accessing these publications that users recognise and abide by the legal requirements associated with these rights.

Take down policy

The Research Portal is Queen's institutional repository that provides access to Queen's research output. Every effort has been made to ensure that content in the Research Portal does not infringe any person's rights, or applicable UK laws. If you discover content in the Research Portal that you believe breaches copyright or violates any law, please contact openaccess@qub.ac.uk. 


\title{
Experimental Investigation of Non-Line-of-Sight Channels in an Intra-Body Network at $2.38 \mathrm{GHz}$
}

\author{
Yomna El-Saboni*, Dmitry E. Zelenchuk*, Gareth A. Conway* and William G. Scanlon ${ }^{\dagger}$ \\ ${ }^{*}$ Centre for Wireless Innovation \\ Institute of Electronics, Communication \& Information Technology, Queen's University Belfast, BT3 9DT, UK \\ Email: \{yelsaboni01, d.zelenchuk, g.conway\}@qub.ac.uk \\ ${ }_{\dagger}^{\dagger}$ Tyndall National Institute, University College Cork, Ireland \\ Email: w.scanlon@ieee.org
}

\begin{abstract}
The characteristics of the intra-body propagation channel between implanted antennas are highly application dependent. Measurements of the forward path gain between identical implant antennas within two multi-layered tissue mimicking liquid phantoms were used to investigate the nature of the intra-body channel at $2.38 \mathrm{GHz}$. One of the antennas was held in fixed locations in the phantoms and a robotic positioner with millimeter accuracy was used to vary the second antenna's position. The results show that the shortest line-of-sight (LOS) path is not always totally dominant and depending on the material layers and dielectric properties other propagation paths may be important. This highlights the importance of careful system design in intra-body networks as the link budget between implanted nodes may need to consider alternative propagating paths, depending on the application scenario.
\end{abstract}

Index Terms-implant, antenna, propagation, biomedical, intra-body network

\section{INTRODUCTION}

Communication between several implantable medical devices could facilitate a wide range of medical applications, enhancing minimally invasive healthcare and long term treatments through, for instance, physiological monitoring of transplanted organs or the control of smart limbs or prosthetics [1], [2]. Within such an Intra-Body Network (IBN) the path between the nodes may be physical short but it is envisaged that some applications will require communication over longer distances and through several tissue types exhibiting different dielectric properties. Examples include the control of urination through neurostimulation in the urinary bladder or the muscle control in spinal injuries or chronic arthritis [3]. Therefore, it is imperative to understand the characteristics of the intrabody channel and establish how signal transmission is affected by node positioning inside the body and the nature of the surrounding tissue structures. While a small number of intrabody numerical studies have appeared in the literature, there needs to be empirical validation of the results. In this paper we utilize a semi-automated mechanical positioner to measure and empirically evaluate the link between two identical insulated antennas embedded within a multi-layered cylindrical tissue mimicking phantom and investigate the effect of varying the direct tissue properties surrounding an antenna on the channel gain.

\section{Measurement of the Intra-Body Channel}

Empirical evaluation of implant to implant channels in nonhomogeneous scenarios is mechanically challenging and requires sophisticated multi-layered phantoms. Therefore, most studies involving IBN channels have only utilized numerical modelling techniques [4], [5], but they have clearly demonstrated how the direct path is not necessarily dominant and that this varies notably from one application to the other according to operating frequency and node positioning.

\section{A. Tissue Mimicking Phantoms}

Two different phantom setups were used in this study. Cylindrical glass containers of $400 \mathrm{~mm}$ height were used to form skin-fat-muscle layered phantoms. The same outer cylinder is used in both setups ( $244 \mathrm{~mm}$ inner diameter, $2 \mathrm{~mm}$ thickness) and is wrapped by a double layer of solid skinmimicking material, $2 \mathrm{~mm}$ thick. The material is described in [6]. The difference between the two phantoms is the diameter of the inner glass cylinder. In Phantom 1, the inner container had an inner diameter of $184 \mathrm{~mm}$ and $3 \mathrm{~mm}$ glass thickness while in Phantom 2, the inner container had an inner diameter of $141 \mathrm{~mm}$ ( $3 \mathrm{~mm}$ thickness), as illustrated in Fig. 1. The long cylindrical form factor of the layered phantom ensures that the dominating wave propagation from the antenna-phantom system is radial and antenna feed cable radiation effects are minimized [7].

The two cylinder approach allows for liquid muscle and fat tissue mimicking regions and the skin layer helps investigate a more realistic scenario where there is a high loss dielectric boundary between fat and air. The muscle equivalent material is described in [7] and the fat equivalent liquid used was Diethylene glycol dibutyl ether [8], with both a good match for the parameters in [9] at $2.38 \mathrm{GHz}$ (Table I).

TABLE I

Tissue Properties AT $2.38 \mathrm{GHz}$

\begin{tabular}{|c|c|c|}
\hline Tissue Type & Relative Permittivity $\epsilon_{r}$ & Conductivity $\sigma \mathrm{Sm}^{-1}$ \\
\hline Muscle & 52.8 & 1.69 \\
\hline Fat & 5.3 & 0.10 \\
\hline Skin & 38.1 & 1.43 \\
\hline
\end{tabular}




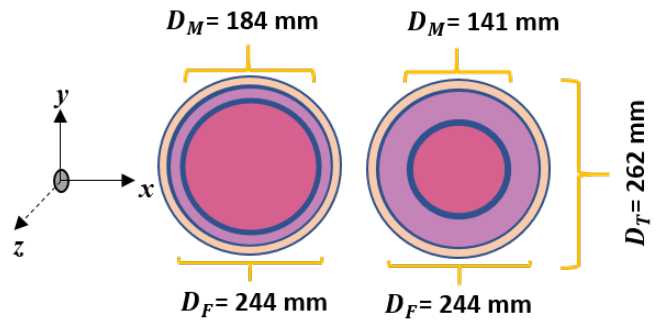

Fig. 1. Schematics of Phantom 1 (left) and Phantom 2 (right).

\section{B. Antennas}

Insulated printed folded meandered dipole (PFMD) antennas were used in this work due to their compact size and robustness across different tissue types without re-tuning [6]. The antennas were always fully immersed inside the tissue equivalent liquid at exactly the center of the phantoms vertical height. The glass containers were always filled with the tissue mimicking liquid to $300 \mathrm{~mm}$ of height to make sure the vertical distance from the center to top or bottom of the phantom liquid is always more than the horizontal distance to outside the phantom. Both antennas (fixed and under test) were held by a $300 \mathrm{~mm}$ long u.fl pigtail connected to a R\&S ZVB8 vector network analyser, calibrated to the antennas feed points.

\section{Robotic Positioner}

A robotic positioner was used to accurately control the movement of one of the antennas across the liquids inside the phantoms. The second antenna was placed at four discrete fixed positions along the $x$-axis (at $x=30,50,80,110 \mathrm{~mm}$ ) where the red line in Fig. 2 illustrates the scan path of the first antenna. The overall setup is illustrated in Fig. 3 and the antenna were attached to a rigid plastic rod to make sure they are oriented correctly.

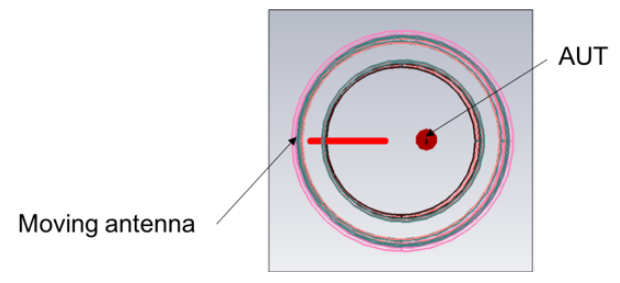

Fig. 2. Positioning of the antennas during measurements.

\section{RESULTS}

The IBN channel was evaluated by measuring the forward path gain $\left|S_{21}\right|$ as one antenna scans away from the second fixed antenna along the $x$-axis and the results are presented in Figs. 4 and 5 for Phantom 1 and Phantom 2, respectively. Four different fixed positions for the second antenna (AUT) were considered and the scanned antenna was positioned at $1 \mathrm{~mm}$ intervals. The gap in the graphs is due to the limitation of the robotic arm, as it approaches the glass boundary in the phantoms. The results to the right of the gap are for cases

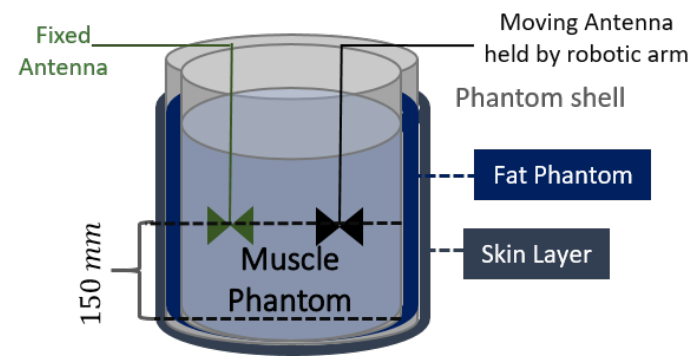

Fig. 3. Illustration of experimental setup showing tissue layers

when the scanned antenna is in the fat region $(x \geq 98 \mathrm{~mm}$ for Phantom 1, $x \geq 79 \mathrm{~mm}$ for Phantom 2).

The measurement results clearly show that the direct LOS path is not always dominant. Particularly for the the cases when both antennas are in the fat region which is either when the AUT is at $110 \mathrm{~mm}$ in both phantoms or the AUT is at $80 \mathrm{~mm}$ in Phantom 2 and the scanned antenna is in the fat region. In both phantoms, when the fixed antenna is at $110 \mathrm{~mm}$ (in the fat region) the LOS distance between the antennas has less effect on forward path gain. The effect of the thicker fat layer in Phantom 2 is also seen in the last two fixed antenna positions $(80,110)$ (Fig. 5) as they exhibit similar behavior.

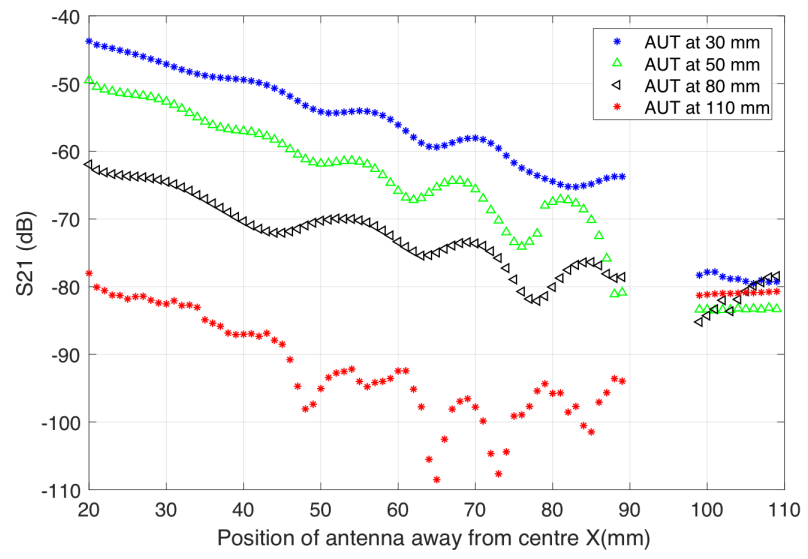

Fig. 4. Measured forward path gain $\left|S_{21}\right|$ in Phantom 1.

\section{CONCLUSION}

This study validates earlier numerical studies of implant to implant channels where the lower loss fat layer plays an important role in the potential link between devices in the human body. The measured forward path gain results are strongly dependent on positioning and the phantom structure. Some of the phenomena observed is related to the geometrical structure of the phantom used, but the results are consistent in terms of the importance of low-loss paths being an important mechanism in IBNs.

Measurement studies of this type are notoriously difficult. In this case, as the fixed antenna was adjusted manually there is the possibility of some positional errors, although this could be mitigated through the use of a second robotic positioner. 


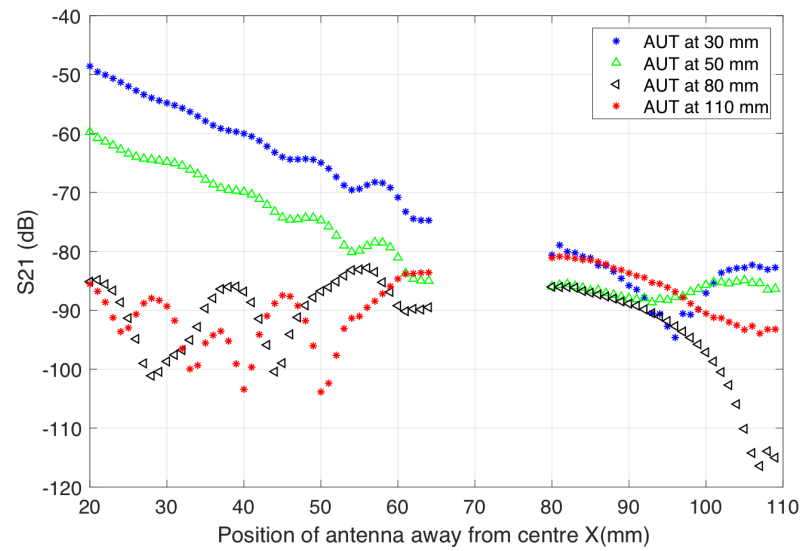

Fig. 5. Measured forward path gain $\left|S_{21}\right|$ in Phantom 2.

\section{REFERENCES}

[1] P. Leelatien, K. Ito, K. Saito, M. Sharma, \& A. Alomainy, "Channel characteristics and wireless telemetry performance of transplanted organ monitoring system using ultrawideband communication,” IEEE J. Electromagn. RF Microw. Med. Biol., vol. 2, 2, pp. 94-101, Jun. 2018.

[2] Z.Y. Chen, Y.M. Gao, \& M. Du, "Propagation characteristics of electromagnetic wave on multiple tissue interfaces in wireless deep implant communication," IET Microwaves, Antennas Propag., vol. 12, 13, pp. 2034-2040, Oct. 2018

[3] J. Massachi, Y.-K. Lo, P.-M. Wang, and W. Liu, "A wireless platform to support pre-clinical trial of neural implant for spinal cord injury," $40^{\text {th }}$ Ann. Intl. Conf. IEEE Eng. Medicine \& Biology Soc. (EMBC), 2018 pp. 5487-5490.

[4] Y. El-Saboni, G.A. Conway, S.L. Cotton, and W.G. Scanlon, "Radiowave propagation characteristics of the intra-body channel at $2.38 \mathrm{GHz}, " 14^{\text {th }}$ Intl. Conf. Wearable \& Implantable Body Sensor Networks (BSN), 2017, pp. 149-152.

[5] Y. El-Saboni, G.A. Conway \& W.G. Scanlon, "Effect of tissue boundaries on the intra-body communication channel at $2.38 \mathrm{GHz}$," Intl. Workshop on Antenna Technology (iWAT), 2017.

[6] M.K. Magill, G.A. Conway \& W.G. Scanlon, "Tissue-independent implantable antenna for in-body communications at $2.36-2.5 \mathrm{GHz}$," IEEE Trans. Antennas Propag., vol. 65, 9, pp. 4406-4417, Sep. 2017.

[7] Y. El-Saboni, M.K. Magill, G.A. Conway, S.L. Cotton \& W.G. Scanlon, "Measurement of deep tissue implanted antenna efficiency using a reverberation chamber,' IEEE J. Electromagn. RF Microwaves Med. Biol., vol. 1, no. 2, pp. 90-97, Dec. 2017.

[8] "Diethylene glycol dibutyl ether, 99+\%, pure, ACROS OrganicsTM 1L; Glass bottle Diethylene glycol dibutyl ether, 99+\%, pure, ACROS OrganicsTM." [Online]. Available: https://www.fishersci.co.uk/shop/products/diethylene-glycol-dibutylether-99-pure-acros-organics-4/10103880. [Accessed: 26-Nov-2018].

[9] S. Gabriel and R.W. Lau, "The dielectric properties of biological tissues: II. Measurements in the frequency range $10 \mathrm{~Hz}$ to $20 \mathrm{GHz}$,' Phys. Med. Biol., vol. 41, no. 11, pp. 2251-2269, Nov. 1996. 